\title{
Contradisciplina: indígenas na pós-graduação e os futuros da antropologia
}

DOI

http://dx.doi.org/10.11606/ 2179-0892.ra.2017.132069

\section{Marcela Stockler Coelho de Souza}

- Universidade de Brasília | Brasília, DF, Brasil

$\checkmark$ macoelhosouza@gmail.com

RESUMO

Tomando como motivo uma sequência de imagens - portas, árvores, fractais, rios e bacias -, este texto procura apontar e comentar alguns dos desafios e implicações para a antropologia em geral - e para a antropologia brasileira em particular - da presença, em nossos estimados espaços de produção dita teórica, de pessoas indígenas e outras, previamente admitidas não como sujeitos, mas como sujeitados, objetos de teorização. O contexto da reflexão é o programa de ações afirmativas que vem sendo implementado pelo Programa de Antropologia Social da Universidade de Brasília (PPGAS/UnB) desde 2014.
PALAVRas-chave

Ações afirmativas; Fim da antropologia; Inter/multidisciplinaridade; Pós-graduação. 
Eu considero que meu trabalho, como filósofa, é ativar o possível, e não descrever o provável; isto é, pensar as situações com e por meio de suas incógnitas, quando posso senti-las

- Isabelle Stengers, A plea for slow science; tradução minha

\section{PORTAS}

Algumas explicações prévias sobre o título-algo panfletário, reconheço, mas os tempos parecem admiti-lo. Procedo de trás para frente, começando pelo futuro.

1. Em uma conferência recente, proferida no Japão, sobre questões que não deixam de ser próximas às que aqui vou procurar abordar, Marilyn Strathern (2015) evoca duas imagens contrastantes de futuro: de um lado, um futuro que se estende como uma estrada adiante em cujo horizonte se perde o olhar; de outro, um futuro que se distribui múltiplo e imprevisível por todos os lados, como portas que abrimos ou se abrem sobre nós. Ela insiste sobre a importância do elemento-surpresa na imagem: essas portas são menos partições que passagens, e como frestas ou biombos de papel por vezes inclusive nos deixariam ver a luz do outro lado... Nestes termos, os futuros da antropologia de que quero falar já estão aqui (alguns pelo menos). Donde a epígrafe: pois, como Stengers, considero que meu trabalho, como antropóloga, é também "ativar o possível, e não descrever o provável; isto é, pensar as situações com e por meio de suas incógnitas, quando posso senti-las" (Stengers, 2011:1-tradução e ênfase minhas).

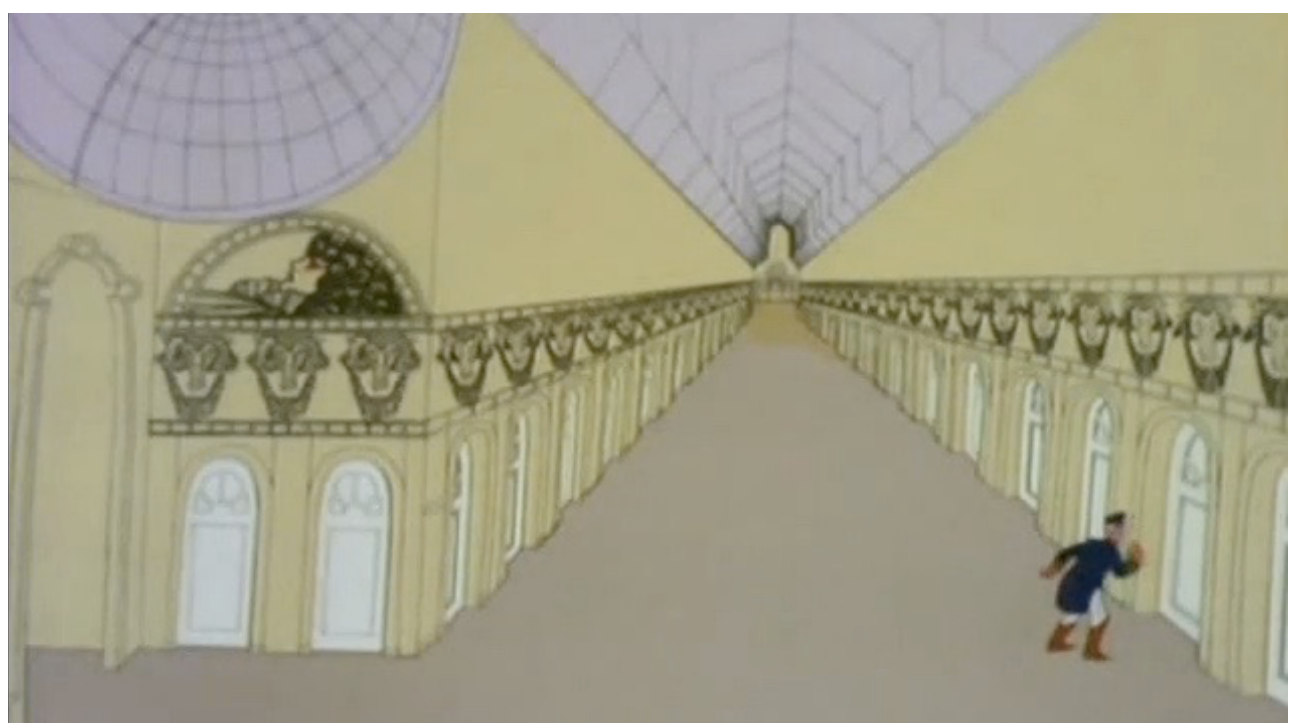

1 Este texto tem uma história que talvez valha mencionar. Foi apresentado em sua forma quase final pela primeira vez em um Seminário do Departamento de Antropologia da UnB, em março de 2016 . O contexto era o primeiro aniversário da primeira turma resultante da política de ações afirmativas do Programa de Pós-Craduação em Antropologia Social da UnB. Ademais, todas as ocasiões em que tive oportunidade de testar essas idéias foram marcadas pelo mesmo espírito de urgência quanto a esta questão, desde o convite dos estudantes da Universidade Federal de Santa Catarina (compromisso que afinal não pude honrar) para falar nas Jornadas Antropológicas (agosto de 2015). Foram elas o Seminário Ações Afirmativas no PPCAS da Universidade Federal do Rio Grande do Sul:

\section{Figura 1:}

Duas imagens de futuro [cena de Yellow Submarine; The Beatles: Yellow Submarine, England, 1968]. A imagem deve ser lida supondose que cada porta se abra para outros corredores, semelhantes a este, com suas próprias portassem que possamos prever se estas nos levarão ou não de volta ao corredor original, como é possível constatar quando se bota a correr entre elas os personagens. 
2. Passando ao foco sobre a presença indígena na pós-graduação-é preciso esclarecer que a tomo aqui sob um viés específico, a saber, o de seus impactos sobre o que se reconhece como conhecimento antropológico, sobre suas formas (e relações) de produção, e sobre seus efeitos. Cabe então explicitar o que este duplo viés - sobre o caso indígena, e sobre a pós-graduação-implica aqui, ou melhor, aquilo que ele deixa de lado, não por negligenciá-lo, mas por tomá-lo como pressuposto, que, insisto, deve ser considerado como pano de fundo de tudo o que se segue.

Em primeiro lugar, tomo o caso indígena como um exemplar-o exemplar que eu conheço - do desafio da "inclusão" (adiante direi algo sobre essa palavra) na pós-gradução por meio de ações afirmativas e em processos desenhados para acolher a diversidade das trajetórias - escolares e existenciais - de sujeitos (individuais e coletivos) histórica, contínua e barbaramente subalternizados da sociedade brasileira. Isto quer dizer que o que eu disser aqui a partir da discussão da presença indígena me parece ter também relevância quanto a outros casos - ainda que eu não esteja no momento preparada para desdobrar neste sentido a reflexão. Mas é fundamental afirmá-lo, para não correr o risco de ser mal-compreendida: como tentarei mostrar, o que há de específico no caso indígena não é uma alteridade substantivamente mais radical qualquer, mas um desenvolvimento histórico particular, contingente, que permite vislumbrar com maior nitidez certos aspectos (e certamente não todos) do problema. A perspectiva da experiência de e com outros sujeitos possivelmente ressaltaria outros aspectos, ou estes mesmos de ângulos diferentes.

Em segundo lugar, a presença de estudantes e pesquisadores com trajetórias assim diversificadas na pós-graduação me parece também poder ser abordada de um outro ângulo, como parte de um movimento muito mais amplo de reconfiguração dos contextos dessas práticas que logram ser reconhecidas como antropológicas. Esse movimento me parece colocar em questão o lugar privilegiado, na realidade quase exclusivo, da pós-graduação na produção de conhecimento. Pense-se na diversificação das carreiras, com antropólogos e antropólogas circulando entre posições na academia, na gestão pública, em ONGs, em movimentos sociais; bem como na diversificação dos "produtos" da sua atividade, das peças técnicas a inúmeras experiências de pesquisa colaborativa, educação intercultural, militância, advocacy etc. Uma reconfiguração dos contextos sociais de produção do conhecimento antropológico está sem dúvida em andamento, o que exige uma reconsideração do modelo hoje prevalecente, com sua quase exclusiva ênfase na pós-graduação. Esse modelo é menos antigo e menos "natural" do que costumamos pensar: e não se pode ignorar que a expansão exponencial dos programas de pós-graduação em antropologia nos últimos 20 anos, em que o modelo se apoia, correspondeu ao engessamento de uma estrutura altamente hierarquizada de distribuição de prestígio ("publica- diálogos com experiências de inclusão e permanência de estudantes indígenas, negros e de pessoas com deficiência na Universidade brasileira (Porto Alegre, 9 e 10 de novembro de 2015), em que apresentei as primeiras reflexões sobre o tema em parceria com o doutorando indígena Francisco Apurinã, e palestras proferidas na mesma universidade em março de 2016 e na Universidade Federal do Paraná por ocasião do encerramento da VIII Semana de Antropologia e Arqueologia/II Seminário de Etnologia e Museus (Curitiba, 22 de setembro de 2016). Tal urgência, que espero aqui transmitir, é obviamente o resultado da insistente "r/existência" dos sujeitos implicados. A presente reflexão, assim, deve principalmente a estes, bem como aos organizadores dos eventos $e$ interlocutores que encontre nessas ocasiões. São muitos para que possa mencionálos nominalmente, mas preciso agradecer a Francisco Apurinã, pelo desafio de uma desorientação constante e cuidadosa sem a qual nada disso teria sido pensado, e a Renato Sztutman, pelo convite para esta publicação e pela leitura cuidadosa e generosa do texto. Obviamente, todas as insuficiências e outros defeitos são de minha exclusiva responsabilidade. 
ções") e financiamento. Esta estrutura, parece-me claro, é incapaz de acolher as forças criativas que se encontram e se provocam nesses outros contextos, e corre o risco de sufocar aquilo que a antropologia teria de mais potente. Isso se articula à questão da "disciplinaridade".

3. Uso aqui a palavra contradisciplina para tentar ativar, na esperança de que isto tenha alguma graça, duas ou três das conotações deste prefixo "contra" - contracultura, contra-colonização (Bispo, 2015), contra-mestiçagem (Goldman, 2015) —em relação aos debates, passados e presentes, relativos ao modo de existência da antropologia como uma disciplina (acadêmica) entre outras disciplinas (acadêmicas). Isto é, aos debates relativos, de um lado, à sua unidade e diversidade "internas", de outro, à sua integração em projetos inter- ou multi-disciplinares. ${ }^{2}$

Sob este aspecto, é preciso dizer que esta reflexão se origina no convite honroso - mas perturbador-dos estudantes de pós-graduação do Programa de Pós-Graduação em Antropologia da Universidade Federal de Santa Catarina (Florianópolis) para compor a mesa de encerramento das Jornadas Antropológicas de 2015, cujo tema era "a antropologia através das antropologias". A chamada nos convidava a tematizar o que permitiria - se é que algo permite - 0 reconhecimento de tudo o que se faz sob essa rubrica como variantes de uma mesma "disciplina". Um outro convite, mais ao sul (para um seminário sobre ações afirmativas na pós-graduação na Universidade Federal do Rio Grande do Sul), me tirou da cilada, sugerindo-me a idéia de abordar o tema de uma perspectiva transversal que pudesse evitar o terreno minado (e ao mesmo tempo batido) do debate proposto e me permitisse escapar ao dilema do "uma ou muitas" antropologias. (E que fosse também uma perspectiva "empírica", isto é, em alguma medida etnográfica, dados os estreitos limites da minha competência filosófica). Decidi que iria tentar pensar o problema então a partir do desafio muito prático de abertura da pós-graduação para estudantes, pesquisadores e intelectuais indígenas, com base em políticas que tomam como ponto de partida o reconhecimento do direito a uma "educação diferenciada" - e que não faz dessa diferenciação, portanto, um impedimento à formação em nível de pós-graduação em centros avaliados como de excelência.

A educação indígena diferenciada é mais geralmente pensada como implicando escolas indígenas, voltadas exclusivamente para alunos indígenas e de preferência com professores do mesmo povo. Esse modelo "separatista" (segregação seria uma palavra bem pior) se impõe mais naturalmente no ensino fundamental e médio - em que a escolarização se dá principalmente nas aldeias; em nível superior, essa alternativa remete às licenciaturas interculturais, e aos projetos de universidade indígena. Um tal modelo não é incompatível, pelo contrário, com políticas de acesso ao ensino superior "universal" - nada diz que o princípio
2 Deixando de lado aqui, provisoriamente, a ideia de transdisciplinaridade; $\mathrm{e}$ passando por cima de um amplo debate para tomar multi e interdisciplinaridade como referindo-se em geral a projetos que assumem como ponto de partida a própria disciplinaridade - as disciplinas como "unidades" pré-constituídas. Este não é evidentemente o único sentido em que essas noções podem ser evocadas 
da educação diferenciada não possa ser aplicado em ambientes não separados. A diferenciação não tem evidentemente a segregação como condição - outra vez, pelo contrário: como em outros casos de "inclusão", o desafio é tomar as "necessidades especiais" dos sujeitos (individual ou coletivamente considerados) não como "deficiências", mas como potências. De maneira que a presença destes nos espaços universitários aparece como condição do florescimento de relações de conhecimento realmente capazes de contrariar os impulsos e efeitos epistemicidas de uma instituição como se sabe erigida com base em preconceitos universalistas e numa estrutura de privilégios racistas, colonialistas, machistas, classistas, capacitistas. Em termos de política para o ensino superior, nada me soa, hoje, mais urgente.

Não vou tematizar aqui o debate sobre a importância desse princípio no delineamento da política de acolhimento e formação dos estudantes indígenas - a não ser para notar que o direito à educação diferenciada implica que esteja bloqueada de saída a possibilidade de interpretar sua diferença como transitória. Os estudantes indígenas sempre chegarão (idealmente) de uma trajetória escolar diferenciada - não pode haver prazo para estas cotas, se é que poderá haver para alguma. Este é um dos aspectos, aliás, em que a especificidade do caso indígena talvez permita ver algo que tende a ficar oculto, mas que nem por isso está ausente: o quanto a perspectiva da transitoriedade das ações afirmativas parece supor os horizontes da aculturação ou da mestiçagem, isto é, uma subsunção da diferença que é ao mesmo tempo o ocultamento da violência que contra ela se dirige. Nestes termos, seu horizonte continua sendo epistemicida. O direito à educação diferenciada reconhecido constitucionalmente aos índios bloqueia esse horizonte - formalmente, é claro, uma vez que o assimilacionismo e sua violência continuam vivíssimos fora da Constituição Federal, inclusive enquanto política de governo, desde antes e ainda mais descaradamente depois do golpe de 2016.

Não vou tampouco tematizar os impactos, já detectáveis, da presença indígena nos contextos acadêmicos de ensino e pesquisa de antropologia geral - este é um tema que merece um esforço à parte. Minha questão é bem mais limitada: refere-se aos efeitos potenciais dessas co-presenças de antropólogo não-indígena e antropólogo indígena (por enquanto, em geral, com o primeiro da posição de professor, o segundo na posição de estudante) sobre o modo como seus praticantes pensamos (e vivemos) o problema da unidade/ diversidade da disciplina. A intenção aqui é adicionar desta maneira um terceiro plano aos dois em que se distribui geralmente este problema: a saber, um plano "interno" em que se distinguem tradições nacionais, estilos filosóficos, estilos teórico-epistemológicos, especializações temáticas ou regionais etc.; e um plano "externo" (de campos e projetos inter ou multidisciplinares) em que 
se dão as relações entre a antropologia e outras disciplinas. Este terceiro plano é transversal ao próprio ordenamento disciplinar; trata-se de um eixo de alteridade interna propriamente constitutiva da antropologia, imanente ao seu método (e a seu modo de construção do objeto), a etnografia, ${ }^{3}$ mas cujo funcionamento vem sendo profundamente alterado por processos diversos, incluindo as experiências aqui em foco. Refiro-me evidentemente à dualidade observado/ observador (aplicável aos agentes, aos discursos, às práticas), sob a forma básica da distinção entre aqueles sobre quem escrevo e àqueles para quem escrevo (a mesma dualidade que se estende naquelas entre discurso ou teoria nativa a ser explicada e discurso ou teoria antropológica que interpreta ou explica, entre etnografia e teoria etc.).

Não é apenas em sala de aula (ou sessão de orientação) que esta distinção se vê agora subvertida (voltarei a isso), mas este é provavelmente o contexto onde estamos menos preparados para encarar tal subversão (etnólogos e etnólogas têm enfrentado isso "no campo" há algum tempo, sob a forma de um questionamento constante dos termos e finalidades de nossas pesquisas e engajamentos). Eu pelo menos estava. Não posso contar o número de vezes em que me senti ruborizar após um uso do pronome "nós", que implicava ao mesmo tempo a inclusão de todos os antropólogos e sua identificação como participantes de uma mesma tradição (ou cultura) - um uso que replicava o jogo de inclusão excludente por meio do qual o indígena (pessoa, discurso) só seria escutado ou recebido quando suficientemente disciplinado (ou "formado"). Pois tudo se passava como se eu estivesse sinalizando para os quatro estudantes indígenas da primeira turma da política de ações afirmativas: "convertam-se à antropologia, incluam-se neste "nós", e então poderemos falar de igual para igual". Para minha iluminação, entretanto, elas e eles - me refiro à "primeira turma", mas também aos que chegaram desde então - se recusa(ra)m: e deste gesto brotam algumas de minhas esperanças de futuro, para a antropologia inclusive...

Não é de hoje que a antropologia se reconhece como ocupando uma posição particular no campo das ciências sociais, talvez por ser provavelmente a que tem maiores problemas com a insistente insujeição de seu suposto "objeto" - as dificuldades com que muitos antropólogos não-indígenas temos nos deparado para acordar protocolos de pesquisa que interessem às comunidades são um sintoma auspicioso dessa irredutibilidade. Não posso deixar de pensar (ou esperar) que esta, operando como um eixo de diversificação transversal àqueles definidos pela lógica disciplinar (e assim transversal aos debates sobre ausência de paradigmas, crise crônica, "fim da antropologia", inter e multidisciplinaridade etc.), opere como um vetor contradisciplinar, ao subverter a regra da hierarquia entre discurso nativo e antropológico nos contextos mesmos que os antropólogos reconhecem como de produção da teoria, interferindo assim com as formas de disci-
3 Para onde quer que vá o método etnográfico-e este já se espalhou bem além da antropologia-segue junto esta sua condição. 
plinarização do próprio pensamento antropológico.

Essas formas de disciplinarização, é preciso que se o diga claramente, expressam e reproduzem a lógica hierárquica que organiza a "produção de conhecimento" acadêmico, em nossa como em outras áreas. Trata-se de uma lógica que, ordenada por uma noção de "produtividade" cuja óbvia inspiração já deveria ter nos colocado em alerta faz muito tempo, confunde os "produtos" - artigos, livros, palestras, orientações-, quantificados enquanto "indicadores" de uma certa atividade criativa, com as fontes e forças vivas desta atividade. A armadiIha do chamado "mérito" é nos fazer confundir esses indicadores com a própria atividade, com o conhecimento que produzimos na forma de criaturas capazes de criar outros conhecimentos (outras criaturas) elas próprias (por isso não são só "produtos"): os textos que escrevemos e que se reescrevem a cada leitor, os estudantes que formamos enquanto eles nos formam professores ${ }^{4}$, os professores que são formados por estudantes enquanto os formam... Espero então conseguir dizer algo sobre esta atividade, e sobre o que me parecem ser condições necessárias à sua vitalidade, em conexão com as mudanças hoje em curso nos contextos, formas e relações de reprodução da tradição de conhecimento que logra ser reconhecida como antropologia, ocupando (por lográ-lo) os espaços legitimados para tal-e vice-versa.

As portas que tenho em mente foram abertas no Programa de Pós-Graduação em Antropologia Social da Universidade de Brasília em 2013. A iniciativa foi estudantil: e uma resolução delineando os parâmetros da política de ações afirmativas foi aprovada pelo colegiado do PPCAS em outubro daquele ano. A política de acesso previa reserva (piso) de vinte por cento das vagas para candidatos autoidentificados como negros na seleção "universal"; e uma vaga de mestrado e outra de doutorado para candidatos indígenas, selecionados por meio de processo específico compreendendo apresentação de um dossiêe entrevista. Com pequenas modificações, essa política orientou os editais de seleção de 2014, 2015 e 2016: são já três turmas de ingressos nesta base. O sucesso foi maior no caso da seleção indígena, em que as vagas foram preenchidas (e em alguns casos ampliadas) em todos os anos - o que não aconteceu no caso das cotas para candidatos autodeclarados negros. ${ }^{5}$ Para além do acesso, a política prevê prioridade na alocação de bolsas para os dois segmentos, e para os alunos indígenas provisão de moradia e alimentação (ideal que vem sendo parcialmente cumprido, e não sem dificuldades, na ausência de uma política institucional de ações afirmativas compreensiva no âmbito da Universidade como um todo). Um "detalhe" importante refere-se à língua estrangeira: para os candidatos indígenas (exclusivamente), a prova, que compõe a seleção, não é eliminatória, e os que não forem aprovados nela deverão então cursar um semestre de inglês instrumental na própria universidade ${ }^{6}$.
4 É curioso que não exista um verbo para a "ação" do orientando sobre o orientador: o orientador orienta o orientando; o orientando... e aqui precisamos empregar a passiva...é orientado... Que tal desorientar?

5 O colegiado do programa debateu essa discrepância e introduziu em 2016 algumas mudanças nas regras com 0 objetivo de tornar a política mais efetiva.

6 Segundo convênio com o Instituto de Letras. Tem crescido a percepção, entre alunos e professores, de que esta formação é insuficiente, sendo necessário estendê-la e fortalecê-la (e não só para alunos optantes). Considero o ponto fundamental: não pode haver política de internacionalização da pós-graduação, por exemplo, tão cara a nossas agências avaliadoras, sem que a universidade pública seja capaz de prover a todos os seus ingressos as condições para a aquisição de uma formação que não é provida pelo sistema de ensino público fundamental e médio. A obrigatoriedade da língua estrangeira nas pós-graduações - enquanto a universidade pública não for capaz de preparar todos os seus graduandos para isso-perpetua obviamente os privilégios de classe e raça daqueles que puderam pagar por essa formação. 
Conquanto os desafios do acesso e da permanência sejam vitais e urgentes - não há ação afirmativa sem que sejam devidamente enfrentados - o foco aqui será, como já disse, outro: não o risco de fracasso das ações afirmativas, mas sim o de seu sucesso, se por isto entendermos sua potência subversiva, aquela de um vetor contradisciplinar capaz quem sabe de contrariar as forças mortíferas que trabalham para reduzir a antropologia a uma atividade voltada para a produção de um conhecimento disciplinado e convertível em moedas e medalhas.

\section{FRACTAIS [EM CASA NA ANTROPOLOGIA?]}

Marilyn Strathern, em um texto de 2015, reflete sobre o lugar da antropologia numa economia baseada na validação do conhecimento como informação convertível em valor transacionável em outras esferas (econômicas, tecnológica, formulação de políticas públicas), e num ambiente em que a inter e multidisciplinaridade vem sendo reinvestidas como paradigmas mesmo da inovação científica. Ela se pergunta num dado momento se, entre a combinação de origens diversas na produção de um conhecimento comum (origens múltiplas, resultado único), e a idéia da recombinação como produção de novas origens, novas possiblidades (origem única, resultados múltiplos), haveria afinal algo mais que queiramos saber.

Notemos que ambas imagens, de fato, nos dão um produto mais ou menos similar (são compatíveis): seja porque a variedade é posta de partida para ser canalizada para um leito comum, seja porque ela resulta da diferenciação interna de um todo dado previamente, em ambos os casos presume-se-ainda que como indagação - a unidade da antropologia como uma "constante", algo que se sustenta ou como origem ou como destino, ou ainda num encadeamento serial desses dois movimentos, um trajeto que todos os antropólogos devem de alguma maneira partilhar mesmo que nem todos o atravessem inteiro... Esse trajeto, feito de convergências e divergências, toma a forma de um crescimento que se dá ora por multiplicação (via divisão) - "da mesma maneira que um conjunto de mudas é dividido para replantagem, a 'divisão' (uma proliferação interna entre elementos de modo que cada um gera um novo crescimento") é uma outra forma da 'multiplicação' " (Strathern, 2015:9) -, ora por adição7. E é esse trajeto que permite "reconhecer" as antropologias do "presente" como conectadas por uma mesma história (de multiplicação, por desdobramento ou metamorfose); é ele que permite enfim à Antropologia se reconhecer como uma. No plano das conexões com a história das disciplinas vizinhas, vale notar como os esforços deliberados para fortalecer projetos e contextos inter ou multidisciplinares têm como contrapartida um aquecimento desse movimento interno de cisão/fusão.

Aceitemos que nossa disciplina só tenha podido "crescer" sob essa forma diversificada e múltipla. Então o que pode (ou pôde) sustentar a antropologia
7 Por meio da subtração? O que uma disciplina precisaria separar e subtrair de si mesma para associar-se a outras trajetórias (in)disciplinares? 
como um contexto em que os antropólogos sintam-se (ou costumassem se sentir) "em casa", mais em casa do que, por exemplo, na filosofia ou na sociologia? Marilyn Strathern aponta para a crítica como um dispositivo avaliativo embutido, interno, às próprias disciplinas - em contraposição às políticas de fomento e avaliação (e a lógica da accountability) centradas na produtividade. Trata-se de um dispositivo que operaria, como ela diz, "em parte para transmitir como é o sentimento de sentir-se em casa na sua própria disciplina" (2006:198 - ênfase minha). Seu exemplo é uma descrição contemporânea do dom em Fidji (Miyazaki, 2006). O que me interessa no texto é esse momento em que Strathern recorre à descrição de Myiazaki do "dom fidjiano", para, diante desde objeto antropológico quintessencial, mostrar como outros dons se alinham, "convocando uma linhagem de análise que apenas um antropólogo pode ensaiar" (Strathern, idem - tradução minha). São os antecedentes que essa linhagem congrega que conferem ao dom fidjiano de Miyazaki sua novidade. Por outro lado, nenhum antropólogo a rememoraria igual; tome-se a sequência que Strathern evoca: Mauss, Gregory, Laidlaw, Sykes e Miyazaki. Unitário por meio do foco argumentativo - dialógico - que é sustentado pela polêmica, o dom é feito múltiplo outra vez por meio mesmo deste esforço crítico que menos o fecha do que o redivide como resultado dos debates. Novas bifurcações.

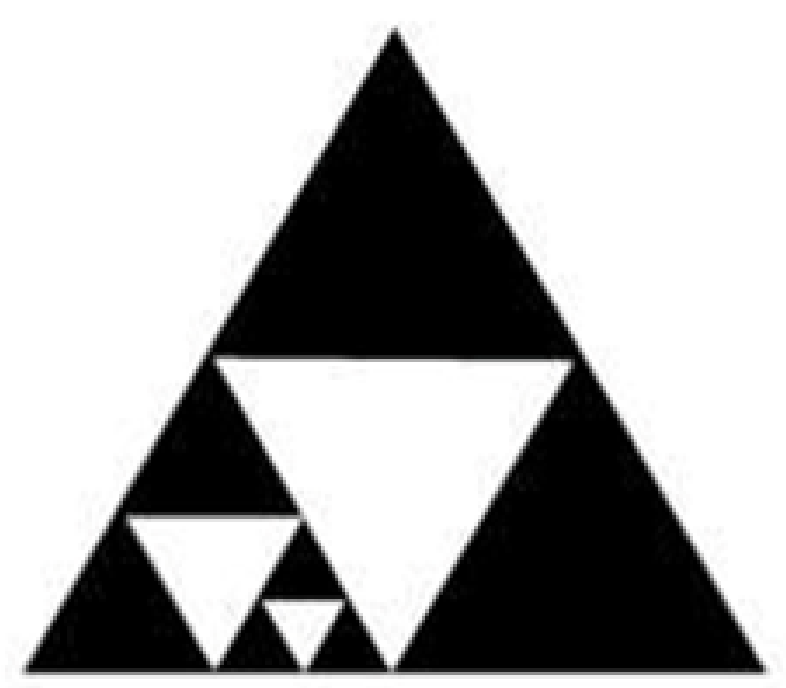

\section{Figura 2:}

Distinções fractais: "o nome captura o fato de que uma tal distinção repete um padrão relacional no interior de si mesma" (Abott, 2001:9). Tratamse de "divisões que mantêm sua forma através de diferentes escalas [...]. A cada instanciação, as distinções reproduzem posições que coalescem em torno de dois conjuntos de valores contrários. O efeito é que os valores são mantidos em relação um ao outro" (Strathern, 2015:130). Assim, na sociologia por exemplo, um divisor quantitativo/qualitativo se encontra tanto na relação da disciplina com a economia como se replica no interior da primeira como uma divisão de método; além disso, internamente ao campo dos métodos qualitativos, o mesmo divisor pode ser reencontrado, e assim por diante. Fractalidade refere-se ao modo como uma tal distinção repete um padrão relacional no interior de si mesma" (idem: 131). (O leitor de Lévi-Strauss não tem como não se sentir em casa.) 
Se já nos sentimos em casa por meio desse jogo de fusões e cisões entre linhagens argumentativas traçadas sobre fenômenos que se veem, com elas, igualmente multiplicados, arrisco-me a dizer que hoje torna-se cada vez mais difícil reconhecer imediatamente uma análise como "quintessencialmente" antropológica. Mesmo do dom (quantos traçaríamos a mesma linhagem que Strathern aqui?). Mesmo do parentesco. Está muito difícil -será só para mim?-sentir-se "em casa" na antropologia. E isso certamente não se deve simplesmente à diversidade de nossas linhagens: aplicando os dois modelos que Strathern delineia para falar da interdisciplinaridade como dispositivo, seja para gerar múltiplos futuros a partir de passados indivisos (um modelo de conhecimento baseado na pesquisa), seja para reconciliar em um futuro indiviso múltiplos passados (um modelo de produção de conhecimento que ela chama gerencial, ligados a projetos interdisciplinares), é fácil reconhecer como os dois movimentos combinados operam internamente à nossa própria (e outras) disciplinas tanto quanto nos espaços (institucionais, conceituais) entre (inter/multi) disciplinas. Afinal, também aqui, parece impossível discernir entre uma diferença que emerge dentro de uma cultura/disciplina e as que emergem entre culturas/disciplinas. A antropologia nunca esteve sozinha... (pense-se nas promíscuas relações com o Direito, desde sempre). Se evoco então essa discussão de Strathern é para me autorizar aqui a prosseguir além das disciplinas, ou talvez (tanto faz) aquém: no sentido, digamos, de uma infra-in-disciplinaridade em que possam florescer as forças do contra. Talvez possamos considerar a questão da presença intelectual indígena nos espaços legitimados do debate disciplinar uma questão deste tipo.
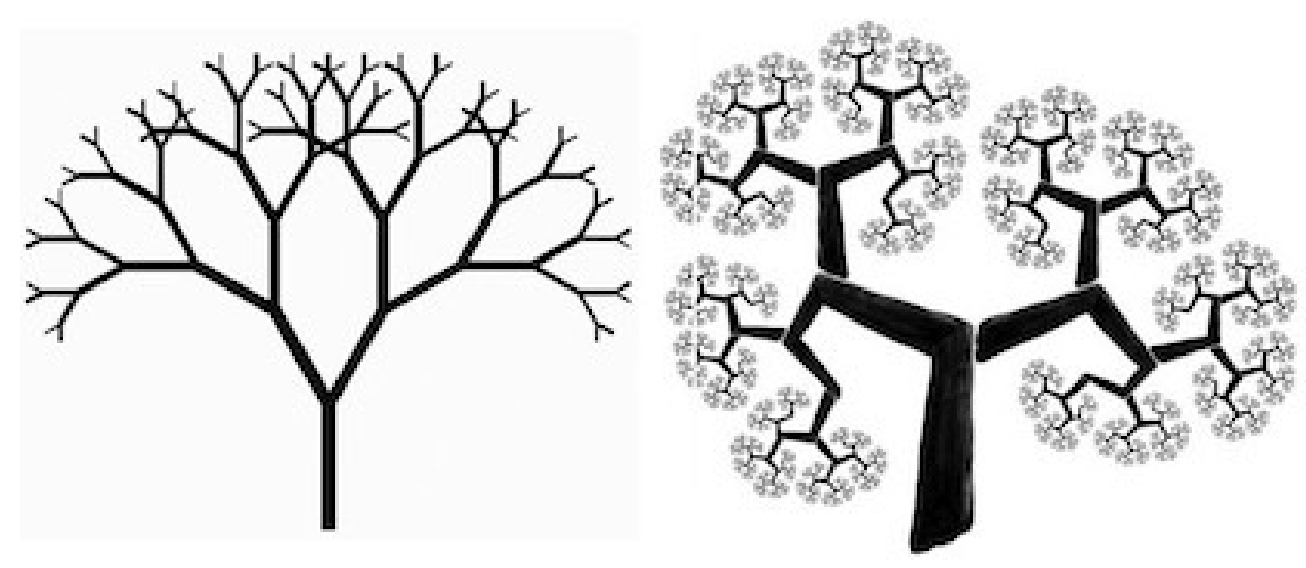

\section{3. ÁRVORES [FILIAÇÃO E ALIANÇAS]}

Justapondo as metáforas de parentesco usadas pelos evolucionistas e pelo discurso da interdisciplinaridade - no primeiro caso, a ancestralidade como 
fonte da "afinidade" (origem singular), no segundo, casamento/afinidade (resultado singular) - Strathern observa como "[a] interdisciplinaridade baseia-se na fusão subsequente do que um dia teve origens distintas, e mantém a mirada, digamos assim, de um futuro indiviso" (Strathern, 2004:38). Mas um futuro indiviso é mesmo algo que devamos, ou mesmo possamos, almejar (o nós aqui é condicional e retrospectivo...)? Seja para a antropologia, seja para um campo inter/multidisciplinar mais amplo em que ela se veja participar?

Continuemos com o parentesco... Por mais de uma razão-nem todas analógicas, nem todas pessoais. Tomemos as considerações de Marisa Peirano em Teoria vivida (2006), que apresentam a relação orientador-orientando como meio de produção - entenda-se, reprodução e inovação - do conhecimento antropológico. A orientação, diz ela, é este momento sui generis em que a teoria é vivida por duas gerações (Peirano, 2006:71) -é por isso que nos é tão difícil separar teoria e história da antropologia, em nossa prática docente sobretudo. Orientador e orientando estão no mesmo barco, pois também o primeiro reviverá de maneira imprevista a teoria, no contexto de sua relaçãoainda que essa relação não seja igualitária. Para especificar a natureza dessa assimetria, entra o retrato da "a figura do orientador, [como aquele que] que [...] no processo de orientação sustenta o diálogo com o passado e o presente da disciplina" (idem:73). Como o "guardião do noviço e da teoria antropológica, e que, portanto, irá dirigir o diálogo dados + teoria. Nessa relação o orientador é um 'elder da tribo', um garantidor da continuidade da disciplina." (idem: ibidem).

O modo como Marisa Peirano usa essas imagens tem vantagens: ela não parece preocupada com a unidade seja "em cima", na origem, seja "em baixo"usando aqui uma orientação espacial para diagramar relações "genealógicas" que só a Europa parece ter desenvolvido, e tardiamente (Bouquet, 1996) ${ }^{8}$; a maioria das imagens nativas dessas relações que conheço (europeias inclusive) faz as "linhagens" crescerem desde o chão, como plantas.... ${ }^{9}$. A disjunção das linhagens é um dado (não há nem posição nem problematização de uma origem comum): o que é importante é sua pluralidade, e o modo como são concretamente instanciadas subjetivamente pelos atores: "a verdadeira linhagem intelectual na antropologia é um produto individual, artesanal portanto, mas com implicações coletivas - ela não pode ser 'ensinada'; ela é o produto da leitura dos clássicos, da experiência etnográfica e da influência de vários mestres" (Peirano, 2016:75).

Mas há aqui lugar para duas observações. A primeira: porque o foco na "garantia da continuidade"? Continuidade de que? Ou de que tipo-se pudermos supor, como me parece óbvio, que uma continuidade sem transformação não qualifi-
8 De fato, parece ter sido necessário esperar por Rivers para que os esquemas arborescentes disseminados ao longo dos séculos XVIII e XIX, e mesmo antes, para fins científicos (diagramas filogenéticos), religosos e seculares ("árvores genealógicas") fossem mobilizados para a conversão de pedigrees britânicos em genealogias antropológicas (Bouquet, 1996)

9 De ramas de batata a carvalhos milenares (cravados na terra por Adão), as imagens vegetais do parentesco são sem dúvida heterogêneas e ricas o suficiente para instigar uma análise mais cuidadosa. A homologia indo-européia entre corpo masculino e árvore (tronco) tem paralelos-e contrastes-em outras partes: penso por exemplo nos troncos terena, ao mesmo tempo indivíduo e coletivo, que vão "sementando em roda" (Pereira, 2009:50; Perini, s/d). Mas seria no mínimo precipidado ver neste simbolismo os mesmos tons patriarcais (e monoteístas) do primeiro... Além disso, a ênfase terena na multiplicação como um aspecto do crescimento nos conduz numa outra direção que a da stasis do diagrama árboreo erigido em registro de conexões objetivas. Em sentido similar, tome-se a imagem canela: esses jê "observam o crescimento de uma vinha de batata doce na qual batatas adicionais aparecem cada vez mais longe ao longo da vinha, distantes de seu ponto de origem e na direção de sua ponta" (Crocker, 1990:266-tradução e ênfase minhas). Éóbvio aqui o interesse do contraste rizomático/ arborescente, mas há ainda outras imagens - transplantes e metamorfoses, por exemplo, também mobilizadas por Strathern no texto que vim discutindo-que valeria explorar. Parece longe de finda a história da modelagem vegetal das relações de conhecimento e de parentesco... 
caria exatamente como crescimento $^{10}$. Além disso, os estudos de parentesco têm colocado bastante em dúvida de que garantir a continuidade seja exatamente o que o elder faz... Mas, em segundo lugar, como boa levistraussiana, é claro que, de meu ponto de vista, falta algo a este parentesco. Digamos: a aliança (exogamia)?

Que a relação entre linhagens da antropologia possa ser imaginada em termos do entrecruzamento de filiações e alianças, é, admito, trivial. Continuaríamos incluindo apenas os mesmos participantes no jogo, um jogo circunscrito pelo princípio que Lévi-Strauss chamou de "endogamia verdadeira", que inclui apenas os reconhecidos previamente como "humanos", no caso aqui "antropólogos" (que nos leem e são lidos por nós). Mas se estamos dispostos - se somos interpelados a-reconhecer como participantes aqueles que antes não eram admitidos tais, aqueles sobre quem escrevíamos, mas não nos liam, nem eram lidos por nós, temos de radicalizar um pouco esta imagem do parentesco e aprender que, como bem sabem os povos indígenas entre outros, a aliança - relações de troca-com Outros tomados como sujeitos é condição de fertilidade de qualquer empreendimento.

Se esta relação é imanente à antropologia, ao seu método etnográfico, não é que "a alteridade" precise se materializar em "informantes", ou em "culturas" ou "grupos" distintos daqueles de onde vêm os antropólogos. Não estou falando da alteridade produzida na base de grandes divisores (e de suas micro-reiterações). Do que falo é desta tensão histórica, essa contradição, entre a equivalência postulada pelo conceito de cultura entre as formas de criatividade dos antropólogos e de seus interlocutores, por um lado, e a assimetria produzida pela separação de contextos que fixa estes últimos "no campo", e faz dos primeiros os participantes exclusivos de um diálogo que se dá al hures - nas universidades. Podemos reconhecer mais, ou menos - sobretudo dos anos 1980 para cá - os múltiplos inputs que, "lá", nos permitem constituir uma voz com que participar do debate "aqui". Mas não podemos mais parar aqui. Não basta a inclusão dos nomes de nossos interlocutores em campo; nem de suas palavras; não basta sequer a inclusão deles nos contextos legitimados da produção de teoria antropológica - a universidade. Não basta nenhum tipo de "inclusão", enquanto isto em que se procura incluí-los, em que eles se procuram incluir, não seja de alguma forma também EXPLODIDO, isto é, espalhado em novas direções.

O que está em questão, parece-me, além do futuro (na "estrada adiante") da disciplina como tal-confesso que isso não me preocupa enormemente -, é a relevância do corpus ou emaranhado de conhecimentos e conceitos que ela acumulou para a detecção e ativação de bons futuros no presente. Isso me preocupa. A história da antropologia neozelandesa contada por Amiria Salmond (Henare, 2007) serve de ilustração para o que tenho em mente: o risco de que a antropologia, incapaz de engajar-se criativamente nos projetos existenciais de seus interlocutores (isto é, de seus supostos "objetos"), acabe por
10 A não ser na lógica da escalaridade tematizada por Anna Tsing (2012), de expansão sem modificação das mesmas relações para outros contextos sem consideração da sua especificidade-como no caso do sistema de plantations... 
arrogar-se a função de criticá-los. Como se a imagem da cultura ou da "visão de mundo maori", forjada desde as primeiras décadas no sec. XX no contexto de uma interação estreita entre movimento político maori e antropologia (britânica), não pudesse consistir em muito mais que um construto ideológico cuja reificação caberia ao acadêmico (esse capaz de reflexividade) denunciar: "em lugar de conceder que os Maori possam conceber as coisas diferentemente, o antropólogo despreza seus relatos como equivocados, ilusórios e, o pior de tudo, indicadivos da trágica ironia de que essas pessoas só possam proclamar sua diferença usando 'nossa' linguagem, porque não são mais eles mesmos" (Henare, 2007:108). Uma tal incompatibilidade separou os antropólogos e os Maori - para o prejuízo, suponho, dos primeiros... A esperança contra esse risco de irrelevância, contudo, não me parece poder ser depositada numa eventual iluminação dos antropólogos.

Para tentar terminar, pois, com esperança, passemos a uma outra família de imagens.

\section{RIOS}

Retomando a formulação do convite para a mesa da UFSC (Florianópolis): "Uma antropologia através das antropologias", um "eixo comum" que "perpassasse" nossas práticas antropológicas em sua pluralidade. A imagem aqui era de um fio que alinhavasse todas as variações - 0 conceito de cultura? de relação (relações sociais)? a etnografia como "método"? Mas um fio também pode ser imaginado como um rio. Aqui nos deparamos com as margensmas margens que não funcionam como limite ou fronteira, o que permitiria substituir a dureza da representação cartográfica pela capilaridade flutuante dos cursos d'água que abrem suas próprias margens na terra. Para

Figura 4: Rios.. além das duas imagens evocadas na chamada, a do "eixo comum" e dos "limites externos", encontram-se noções capazes de subverter os termos já algo batidos, e as aporias, a que nos leva a pergunta posta por meio das imagens de essência ou fronteira: a saber, a vida como simbiose, co-existência e co-constituição de ambientes e ambientados, de rios e margens... 
Ou ainda, podemos pensar em bacias, que nos fornecem modelos bastante variados e sugestivos...

Seja onde for que esses rios nos levem, podemos estar certos de que o fim da antropologia, seja por implosão ou explosão, ou ambas as coisas ao mesmo tempo, é um fantasma, sabe-se, tão antigo quanto a própria disciplina: com isso, não quero dizer que não possa ocorrer no futuro-quero dizer que está acontecendo todo o tempo. Há entretanto diferentes versões desse fantasma, e pelo menos um deles toma a forma de uma esperança.

$\mathrm{Na}$ aula inaugural na UFRGS, em que uma versão anterior deste texto foi apresentada, comecei lembrando que da última (e primeira) vez que estivera lá, para aquele memorável evento sobre políticas de inclusão em 2015, me impressionou (entre muitas coisas) a entrevista em vídeo de um estudante indígena falante de quechua, participante do programa Erasmus em Portugal, que acabou abandonando a universidade (e o programa) para tornar-se xamã. Perguntei-me se do ponto de vista daqueles que estamos nos esforçando para discutir as políticas de "inclusão", consideraríamos esse caso como um "fracasso". Confesso que, do meu ponto de vista, ele foi tão bem sucedido como são os antropólogos que estudam xamanismo para virar... (em geral) antropológos, e não xamãs. Proponho, então, uma nova analogia: o índio na universidade como antropólogo no campo. Acho que devemos levá-la a sério não apenas por questões éticas (como não retribuir o tratamento que gerações de etnólogos e etnólogas recebemos nas aldeias, a paciência infinita de nossos interlocutores em responder questões que no mais das vezes não sabemos fazer?), mas porque foi assim que nos pudemos nos tornar um pouco [como] "indígenas" (ou como quaisquer outras pessoas que estudamos), não nos identificando a elas, obviamente (e muito menos pretendendo representá-las de qualquer maneira que seja), mas tentando deformar as línguas e conceitos recebidos (em particular, da antropologia) de modo a não trair demais (e sobretudo não neutralizar) aquilo que fomos capazes de aprender em nossas experiências de campo. Se somos bem sucedidos, acabamos produzindo uma língua um tanto estranha, que não deixa de nos tirar de nós mesmos (a contragosto ou não) - a autodeterminação do outro é afinal a alter-determinação do Eu (Viveiros de Castro, 2015:11). Que uso uma tal operação teria para os que chegam à academia vindo da outra direção? Não me arrisco, pois não me cabe, e certamente não creio possível, 
prever em que sentido uma contra-antropologia indígena caminhará, mas é bem provável que não seja - seria absurdo tentar forçar que seja - prioritariamente no sentido de produzir mais antropologia...

Nesta conexão, é preciso mencionar a obra única que é o livro de Davi Kopenawa e Bruce Albert, A queda do се́u (2015), como um exemplo do que seria talvez um avatar - ou mesmo a mais perfeita realização - do, tomando emprestado com alguma liberdade o termo de Alcida Ramos, podemos chamar "etnologia à brasileira", que se caracterizaria por um envolvimento de longo-prazo, distribuindo-se em campos intermitentes, marcado pela multiplicidade de posições que o antropólogo é chamado a ocupar na relação com as comunidades que estuda (sobretudo de militância e advocacia). Com a curiosidade de que seus autores são um yanomami e um francês... Parece-me em todo caso que o pacto etnográfico que o sustenta pode se materializar em outros ambientes.

Está na hora de potencializar essas iniciativas, duplicar o diálogo-e pensar o que exigirá de nós fazer com que ele seja de mão dupla nesse território que costumamos pensar como exclusivamente "nosso", a academia. Os pós-graduandos indígenas não são e não podem ser antropólogos como "nós" ou quem quer que seja; eles apenas podem sê-lo a seu modo - o que é verdade de todos os pós-graduados, afinal-e a "nossa" antropologia talvez ganhe algo com isso. Mas isso exige um nem sempre indolor questionamento de nossas práticas - em sala de aula, nas orientações, nas formas de avaliação etc. Tratam-se de microcomportamentos, de expectativas, de modos de relação "naturalizados", que precisamos começar a estranhar, e contra os quais precisaremos nos insurgir.

Afinal, para finalizar outra vez com Isabelle Stengers: "É sempre uma má ideia designar algo para englobar aqueles que se recusam a ser englobados por algo mais" (2005:995).

Marcela Stockler Coelho de Souza tem mestrado e doutorado em Antropologia Social pela Universidade Federal do Rio de Janeiro. Atualmente é professora do Departamento de Antropologia da Universidade de Brasília.

\section{REFERÊNCIAS BIBLIOCRÁFICAS}

ABBOTT, Andrew

2001 Chaos of Disciplines. Chicago e Londres, The University of Chicago Press. 
BOUQUET, Mary

1996 "Family Trees and Their Affinities: the Visual Imperative of the Cenealogical Method". Man v. 2, n. 1: 43-66.

COLDMAN, Marcio

2015 '"Quinhentos anos de contato': por uma teoria etnográfica da (contra)mestiçagem". Mana v. 21, n. 3: 641-659.

KOPENAWA, Davi e ALBERT, Bruce

2015 A queda do céu: palauras de um xamã Yanomami.

São Paulo, Companhia das Letras.

MIYAZAKI, Hirokazu

2006 The Method of Hope: Anthropology, Philosophy, and Fijian Knowledge. Stanford, Stanford University Press

PEIRANO, Mariza

2006 "A teoria vivida: reflexões sobre orientação em antropologia". In: A teoria vivida e outros ensaios de antropologia. Rio de Janeiro, Jorge Zahar Editor, pp. 71-77.

PEREIRA, Levi M.

2009 Os Terena de Buritis: formas organizacionais, territorialização e representação da identidade étnica. Dourados, Ed. da UFCD.

PERINI, Carolina

s/d "Sobre viver em troncos: metáforas vividas, terra, corpo e parentesco entre os Terena de Cachoeirinha". Artigo em elaboração.

STENGERS, Isabelle

2005 "The Cosmopolitical Proposal". In: LATOUR, B. e WEIBEL, P. (eds.) Making Things Public: Atmospheres of Democracy. Cambridge, MIT Press, pp. 994-1003.

2011 "Another Science is Possible! A Plea for Slow Science". Inaugurational Lecture Chair Willy Calewaert 2011-2012, Faculté de Philosophie et Lettres, Université Libre de Bruxelles. 
BISPO, Antonio

2015 Colonização, quilombos: modos e significados. Brasília, Instituto Nacional de Ciência e Tecnologia de Inclusão no Ensino Superior e na Pesquisa (INCTI-UnB/CNPq).

STRATHERN, Marilyn

2015 "Being One, Being Multiple: A Future for Anthropological Relations". NatureCulture.v. 3: 122-157.

TSING, Anna L.

2012 "On Nonscalabitiy: The Living World is not Amenable to Precisionnested Scales". Common Knowledge v. 18, n. 3: 505-524.

VIVEIROS DE CASTRO, Eduardo

2015 "Who is Afraid of the Ontological Wolf? Some Comments on an Ongoing Anthropological Debate". The Cambridge Journal of Anthropology v. 33, n. 1: 2-7. 


\section{ABSTRACT}

Taking a sequence of images - doors, trees, fractals, rivers and basins - as motives, this text tries to point to and comment on some of the challenges and implications for anthropology, and for Brazilian anthropology in particular, of the presence of indigenous and other persons previously admitted as subjected subjects in our cherished spaces of theory making. The context is the affirmative action program that has been implemented at the Postgraduate Program of Social Anthropology at Brasilia University since 2014.

\section{KEYWORDS}

Affirmative action; End of anthropology; Inter/ multidisciplinarity; Postgraduate programs

Recebido em 08.03.2017. Aceito em 22.04.2017. 